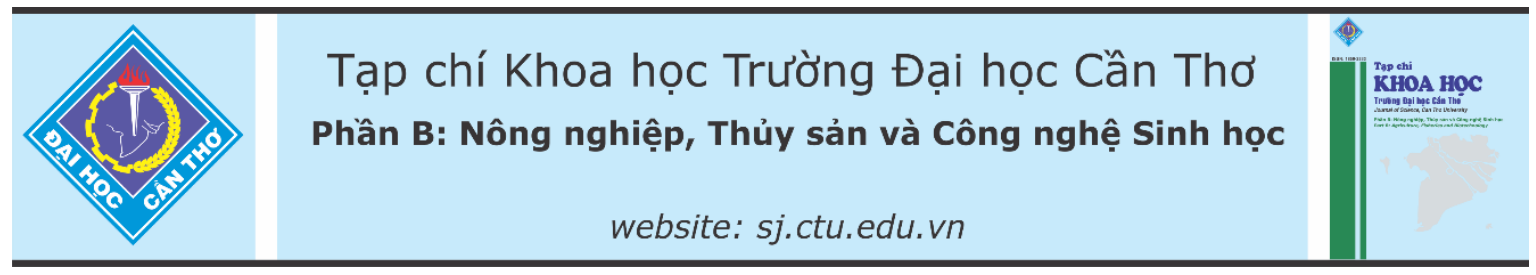

DOI:10.22144/ctu.jvn.2021.097

\title{
HIÊUU QUẢ CỦA PHÂN GÀ, PHÂN TRÙN QUẾ VÀ PHÂN HÓA HỌC ĐẾN SINH TRƯởNG, NĂNG SUẤT VÂ CHẤT LƯợNG TRÁI ĐẬU BĂP ĐỎ (Ảbelmoschus esculentus (L.) Moench)
}

\author{
Tất Anh Thư ${ }^{1 *}$, Lê Vĩnh Thúc ${ }^{1}$, Đặng Kiều Nhân ${ }^{2}$ và Bùi Triệu Thương ${ }^{1}$ \\ ${ }^{1}$ Khoa Nông nghiệp, Trường Đại học Cần Tho \\ ${ }^{2}$ Viện Nghiên cưu Phát triển Đồng bằng sông Cửu Long, Truờng Đại học Cần Tho \\ *Người chịu trách nhiệm về bài viết: Tất Anh Thu (email: tathu@ctu.edu.vn)
}

\section{Thông tin chung:}

Ngày nhận bài: 08/10/2020

Ngày nhận bài sưa: $24 / 11 / 2020$

Ngày duyệt đăng: 25/06/2021

Title:

Effect of different sources of chicken organic manure, vermicompost and chemical fertilizer on growth, yield and nutrient content of okra (Abelmoschus esculentus (L.) Monech)

\section{Tù khóa:}

Cây đậu bắp, phân gà, phân trùn quế và phân hóa học

\section{Keywords:}

Chemical fertilizer, chicken organic fertilizer, okra, vermicompost

\begin{abstract}
The objective of this study is to evaluate the effects of different nutrient supplies and fertilizer dosage on the growth, yield, and quality of Red okra309. The experiment was carried out in a random complete block design with two factors and three replications. Factor A is three fertilizer formulas: (1) $120 \mathrm{~N}-60 \mathrm{P}_{2} \mathrm{O}_{5}-60 \mathrm{~K}_{2} \mathrm{O}$, (2) $60 \mathrm{~N}-30 \mathrm{P}_{2} \mathrm{O}_{5}$ - $30 \mathrm{~K}_{2} \mathrm{O}$ and (3) $30 \mathrm{~N}-30 \mathrm{P}_{2} \mathrm{O}_{5}-30 \mathrm{~K}_{2} \mathrm{O}$ ). Factor $\mathrm{B}$ is the three different sources of nutrient (1) chemical fertilizers, (2) vermicompost and (3) chicken organic manure. Necessary amount of nitrogen is provided by the applied fertilizer source itself, and insufficient phosphorus and potassium will be supplemented from mineral phosphorus and potassium fertilizers (monomers). Data were collected on growth and yield parameters including plant height $(\mathrm{cm})$, plant diameter $(\mathrm{cm})$, chlorophyll index, fruit length, fruit diameter, number of fruits and yield. The results showed that different nutritional sources have a significant effect on yield and quality of okra fruit. In addition, application of chemical fertilizers resulted in the lowest Brix level and the highest $\mathrm{NO}_{3}$ content. In contrast, organic fertilizers gave a high Brix level and a lower $\mathrm{NO}_{3}$ content than chemical fertilizers. Chicken manure and chemical fertilizers gave equal fruit diameter, number of fruits and fresh fruit yield, reaching the highest statistically significant differences compared with worm fertilization. There is a very strong positive correlation between yield and quality with fertilizer type and $N$ dosage.
\end{abstract}

\section{TÓM TẮT}

Nhằm đánh giá ảnh hưởng của các nguồn cung cấp dinh duỡng khác nhau và liều luợng phân bón đến sự phát triển, năng suất và chất luợng trái đậu bắp đỏ Rado 309. Thi nghiệm được bố tri theo thể thức khối hoàn toàn ngẫu nhiên, hai nhân tố, ba lần lạp lại. Nhân tố A là ba công thức phân bón (1) $120 \mathrm{~N}-60 \mathrm{P}_{2} \mathrm{O}_{5}-60 \mathrm{~K}_{2} \mathrm{O}$, (2) $60 \mathrm{~N}$ $-30 \mathrm{P}_{2} \mathrm{O}_{5}-30 \mathrm{~K}_{2} \mathrm{O}$ và (3) $30 \mathrm{~N}-30 \mathrm{P}_{2} \mathrm{O}_{5}-30 \mathrm{~K}_{2} \mathrm{O}$ ). Nhân tố $\mathrm{B}$ là ba nguồn cung cấp dinh dương (1) phân hóa học, (2) phân trùn quế và (3) phân gà. Luoơng đạm cần thiết được đáp ứng bởi chinh nguồn phân bón, luợng lân và kali không đủ đáp ứng sẽ được bổ sung thêm tù phân lân và phân kali (dạng phân đơn). Các chỉ tiêu theo dõi gồm chiều cao cây (cm), đường kính cây (cm), chi sổ SPAD, chiều dài trái, đường kính trái, số tráil/cây và năng suất. Kết quả cho thấy các nguồn cung cấp dinh dương khác nhau cóảnh hưởng rõ rệt đến năng suất và chất luợng trái đậu bẳp. Bón phân hóa học có độ Brix thấp nhất và hàm lượng $\mathrm{NO}_{3}$ c cao nhất. Ngược lại, bón phân hưu co (phân gà và phân trùn quế) cho độ Brix cao và hàm luợng $\mathrm{NO}_{3}$ thấp hơn so với bón phân hóa học. Phân gà và phân hóa học cho đường kính trái, số trái/cây và năng suất trái turơ ngang bằng nhau và cao hơn so với bón phân trùn quế. Có mối tuoong quan thuận giữa năng suất và chất luợng trái với loại phân và liều lượng $N$. 


\section{GIỚI THIẸU}

Cây đậu bắp xanh (green okra) và đậu bắp đỏ (Red Burgundy Okra) thuộc họ Malvaceae được xem là loại rau ăn trái có giá trị kinh tế cao được nhiều trồng ở các vùng nhiệt đới và cận nhiệt đới (Andras et al., 2005; Oyelade et al., 2003). Cây sinh trưởng phát triển mạnh, ưa nắng, kháng bệnh tốt, trái màu đỏ đậm. Năng suất cao hơn gấp 2-3 lần đậu bắp xanh (Phillip et al., 2019). Cây có khả năng chống chịu với điều kiện bất lợi của môi trường (Gunawardhana et al., 2011). Tại các nước trên thế giới, đậu bắp đỏ còn được xem như nguồn thực phẩm chức năng tiềm năng (Irshad et al., 2018; Gul et al., 2015). Tại Việt Nam, cây đậu bắp đỏ là giống cây trồng mới nhu do có thể đáp ứng được nhu cầu thẩm mỹ dùng để trang trí, trồng làm cảnh. Bên cạnh đó, trong trái đậu bắp đỏ còn chứa nhiều carotenoid, anthocyanin, polyphenol, bioflavonoid, ellagic acid,... Các dưỡng chất này đã được chứng minh có ích trong việc ngăn ngừa bệnh ung thư, các bệnh mãn tính (thoái hóa dây thần kinh, bệnh tim mạch) và tăng cường hệ thống miễn dịch (Polturak et al., 2017; Irshad et al., 2018), cùng với đậu bắp xanh, đậu bắp đỏ đang được khuyến khích đưa vào thực đơn hàng ngày.

Sử dụng phân bón hóa học với liều lượng cao chủ yếu là phân đạm là một trong các nguyên nhân làm suy giảm độ phì nhiêu đất, ô nhiễm môi trường, đồng thời còn ảnh hưởng đến phẩm chất, chất lượng nông sản, ảnh hưởng đến sức khỏe của con người do tích lũy nitrate, đặc biệt là cây đậu bắp có thời gian canh tác ngắn và là thực phẩm chính sử dụng hàng ngày (Mahajan et al., 2008). Theo Li et al. (2015), lạm dụng phân bón hóa học không chỉ gây ra hiệu quả sử dụng phân bón thấp, mất cân đối dinh dưỡng mà còn dẫn đến suy thoái môi trường và mất đa dạng sinh học. Nhiều nghiên cứu cho thây phân trùn quế có chứa các nhóm sinh vật có hoạt tính cao như vi khuẩn, hệ vi khuẩn cố định đạm tự do, vi khuẩn phân giải lân, phân giải cellulose và các chất xúc tác sinh học (enzyme) như amylase, lipase, cellulase và chitinase các vi sinh vật này vẫn tiếp tục hoạt động khi phân được bón vào đất, các vi sinh vật này trong quá trình sống đã sản xuất ra các chất điều hòa sinh trưởng thực vật giúp cây sinh trưởng tốt (Zucco et al., 2015). Phân trùn quế không chỉ giúp cải thiện dinh dưỡng trong đất mà còn giúp gia tăng sự tăng trưởng, phát triển và năng suất của một số cây trồng như cải xoong (Masciandaro et al., 1997), cà chua (Arancon et al., 2003), đậu xanh (Ali and Moghadasi, 2015) và bắp (Zaremanesh et al., 2017). Bên cạnh phân trùn quế, phân gia cầm, phân chuồng cũng được xem là một trong các loại phân hữu cơ có nhiều tiềm năng và lợi ích khi sử dụng như gia tăng năng suất và chất lượng rau (Khandaker et al., 2017). Sử dụng phân hữu cơ thay thế phân bón hóa học là một hướng đi mới có ý nghĩa quan trọng trong sản xuất nông nghiệp hữu cơ. Từ đó, thí nghiệm được thực hiện nhằm xác định ảnh hưởng của phân gà hữu cơ, phân trùn quế và phân hóa học đến sinh trưởng, năng suất và chất lượng trái đậu bắp, xác định lượng loại phân và liều lượng phân hữu phù hợp với cây đậu bắp đỏ, giúp cây phát triển tốt cho chât lượng trái và năng suất cao hoặc ngang bằng phân bón hóa học.

\section{VÂT LIÊUU VÀ PHƯƠNG PHÁP NGHIÊN CÚU}

\subsection{Vật liệu nghiên cứu}

Giống đậu bắp sử dụng trong thí nghiệm là giống đậu bắp đỏ Rado 309 (Red Burgundy; Red Okra), là giống mới du nhập vào Việt Nam. Túi $\mathrm{PE}$ hai lớp trắng đen, có đường kính $40 \mathrm{~cm}$ và chiều cao $40 \mathrm{~cm}$ và thân túi có đục lỗ để thoát nước được sử dụng thay chậu trồng cây thông thường. Phân hóa học sử dụng gồm urea $(46 \% \mathrm{~N})$, super lân $\left(16 \% \mathrm{P}_{2} \mathrm{O}_{5}\right)$ và $\mathrm{KCl}\left(60 \% \mathrm{~K}_{2} \mathrm{O}\right)$. Phân hữu cơ sử dụng trong thí nghiệm là phân trùn quế và phân gà dạng viên. Lượng dinh dưỡng trong phân hữu cơ được trình bày trong Bảng 1. 
Bảng 1. Thành phần hóa học của phân gà dạng viên và phân trùn quế dùng trong thí nghiệm

\begin{tabular}{|c|c|c|c|}
\hline \multirow{2}{*}{ Chỉ tiêu đánh giá } & \multirow{2}{*}{ Đơn vị } & \multicolumn{2}{|c|}{ Phân hữu cơ } \\
\hline & & Trùn Quế & Phân Gà \\
\hline $\mathrm{pH}_{\mathrm{H} 2 \mathrm{O}}(1: 2,5)$ & & 6,51 & 6,45 \\
\hline Chất hữu cơ & $\% \mathrm{CHC}$ & 52,03 & 72,00 \\
\hline Đạm tổng số & $\% \mathrm{~N}$ & 1,88 & 3,50 \\
\hline P hữu dụng & $\% \mathrm{P}_{2} \mathrm{O}_{5}$ & 1,05 & 2,50 \\
\hline Kali hữu dụng & $\% \mathrm{~K}_{2} \mathrm{O}$ & 0,29 & 2,50 \\
\hline $\mathrm{CaO}$ & $\%$ & 1,18 & 3,08 \\
\hline $\mathrm{MgO}$ & $\%$ & 0,27 & 1,20 \\
\hline $\mathrm{N}$ hữu dụng $\left(\mathrm{NH}_{4}^{+}-\mathrm{N}\right.$ và $\left.\mathrm{NO}_{3}^{-}-\mathrm{N}\right)$ & $\mathrm{mg} / \mathrm{kg}$ & 1.080 & 7.081 \\
\hline $\mathrm{N}$ hữu cơ & $\%$ & 1,77 & 2,79 \\
\hline N labile & $(\mathrm{mgN} / \mathrm{kg})$ & 590 & 1.939 \\
\hline Tỷ sô C:N & & 16,05 & 11,93 \\
\hline
\end{tabular}

Đất thí nghiệm được thu trên nền đất phù sa bạc màu luân canh lúa - màu tại ấp Tích Thiện, xã Thiện Mỹ, huyện Trà Ôn, tỉnh Vĩnh Long thuộc nhóm đất Gleyic Fluvisol (FAO). Mẫu đất được thu ở tầng mặt
(0 - $20 \mathrm{~cm})$. Đất sau khi thu được để khô tự nhiên, băm nhỏ khoảng $2 \mathrm{~cm}$, trộn đều cho vào túi $\mathrm{PE}$ với khối lượng $8 \mathrm{~kg} /$ túi. Thành phần lý - hóa học của mẫu đất thí nghiệm được trình bày trong Bảng 2 .

Bảng 2. Đặc tính đất thí nghiệm thu từ đất phù sa bạc màu luân canh lúa - màu tại ấp Tích Thiện, xã Thiện Mỹ, huyện Trà Ôn, tỉnh Vĩnh Long

\begin{tabular}{|c|c|c|c|c|c|c|c|c|c|}
\hline pHн2O & $\mathbf{E C}_{(1: 2,5)}$ & CHC & CEC & Nts & Pts & Dung trọng & \multicolumn{3}{|c|}{ \% Cấp hạt } \\
\hline$(1: 2,5)$ & $\mathbf{m S} / \mathbf{c m}$ & $\%$ & meq/100g đất & $\%$ & $\% \mathrm{P}_{2} \mathrm{O}_{5}$ & $\mathrm{~g} / \mathrm{cm}^{3}$ & Cát & Thịt & Sét \\
\hline 5,63 & 0,64 & 4,62 & 12,80 & 0,17 & 0,15 & 1,26 & 1,36 & 53,54 & 45,10 \\
\hline
\end{tabular}

\subsection{Phương pháp nghiên cứu}

Thí nghiệm thực hiện từ 8/2019 đến 11/2019 được và được bố trí theo kiểu khối hoàn toàn ngẫu nhiên, hai nhân tố, ba lần lặp lại, mỗi lặp lại có 3 chậu (1 cây/chậu). Nhân tố chính $\left(\mathrm{F}_{\mathrm{A}}\right)$ là ba mức độ phân bón, lượng phân bón tương ứng đạm $(\mathrm{N})$, lân $\left(\mathrm{P}_{2} \mathrm{O}_{5}\right)$ và kali $\left(\mathrm{K}_{2} \mathrm{O}\right)$ như sau: (1) $120-60-60,(2)$ $60-30-30$, và $(3) 30-30-30$. Nhân tố phụ $\left(\mathrm{F}_{\mathrm{B}}\right)$ là ba loại phân bón (1) phân hóa học, (2) phân trùn quế và (3) phân gà. Lượng phân trùn quế và phân gà được tính toán dựa trên hàm lượng $\mathrm{N}$ có trong phân (Bảng 1) và lượng lân và kali sẽ được bổ sung thêm từ phân bón hóa học. Phân bón được chia thành 5 lần bón (01 lần bón lót và 04 lần bón thúc). Bót lót toàn bộ lượng phân hữu cơ và super lân. Phân urea và kali clorua được dùng để bón thúc. Thời điểm 10 ngày sau khi trồng (NSKT) và 20 NSKT bón $1 / 6$ lượng $\mathrm{N}$ và $1 / 6$ lượng kali. Thời điểm $30 \mathrm{NSKT}$ và $40 \mathrm{NSKT}$ bón $2 / 6$ lượng $\mathrm{N}$ và $2 / 6$ lượng kali.

Bảng 3. Lượng phân hữu cơ cần cung cấp trong thí nghiệm

\begin{tabular}{llrr}
\hline Nghiệm thức & \multirow{2}{*}{ Loại phân bón } & $\begin{array}{r}\text { Lượng phân bón sử dụng cho } \\
\text { 1ha }\end{array}$ & $\begin{array}{r}\text { Lượng } \mathbf{N} \text { cung cấp cho } \\
\text { 1ha }\end{array}$ \\
\hline NPK hóa học & Urea $(46 \% \mathrm{~N})$ & $260,9 \mathrm{~kg} / \mathrm{ha}$ & $120 \mathrm{~kg}$ \\
Phân gà & Phân gà $(3,5 \% \mathrm{~N})$ & 3,43 tấn & $120 \mathrm{~kg}$ \\
Phân trùn quế & Phân trùn quế $(1,88 \% \mathrm{~N})$ & 6,38 tấn $/ \mathrm{ha}$ & $120 \mathrm{~kg}$ \\
\hline
\end{tabular}

2.3. Thu thập các chỉ tiêu nông học, năng suất và đánh giá chất lượng trái đậu bắp

Các thông số liên quan đến sự sinh trưởng của cây được đánh giá: chiều cao cây $(\mathrm{cm})$, dường kính gốc $(\mathrm{cm})$, chỉ số diệp lục (SPAD) được xác định tại bốn thời điểm 15 NSKT, 30 NSKT, 55 NSKT và 80 NSKT.Các thông số liên quan đến năng suất: chiều dài trái $(\mathrm{cm})$ và đường kính $(\mathrm{cm})$, số trái/cây, năng suất/cây (g/cây).Các thuộc tính sau thu hoạch (chất lượng trái) được đánh giá là: \% độ brix, hàm lượng nitrate $(\mathrm{mg} / \mathrm{kg}$ trái tươi).

2.4. Phương pháp phân tích mẫu đất và mẫu cây

2.4.1. Phuơng pháp phân tích mẫu đất và mẫu phân bón hữu co

Các chỉ tiêu phân tích mẫu đất được tuân thủ theo đúng phương pháp phân tích chuẩn phổ biến ở tất cả các phòng phân tích đất (Houba et al., 1998) cụ thể như sau: $\mathrm{pH}$ đất và $\mathrm{EC}$ đất $(\mathrm{mS} / \mathrm{cm})$ được trích bằng nước cất $(1: 2,5)$, sau đó được đo bằng $\mathrm{pH}$ kế 
và $\mathrm{EC}$ kế. Chất hữu cơ trong đất $(\% \mathrm{C})$ được xác định bằng phương pháp của Walkley Black (1934). Hàm lượng các cation (kali, canxi và magiê) được ly trích bằng dung dịch $\mathrm{BaCl}_{2} 0,1 \mathrm{M}$ không đệm, dung dịch sau ly trích được đo trên máy hấp thu nguyên tử. Lân dễ tiêu (theo phương pháp Bray II). Đạm hữu dụng (ammonium và nitrate) được ly trích bằng $\mathrm{KCl} 2 \mathrm{M}$ tỷ lệ $1: 10(\mathrm{w} / \mathrm{v})$, xác định theo phương pháp so màu ở bước sóng $650 \mathrm{~nm}$ (ammonium) và $540 \mathrm{~nm}$ (nitrate). Đạm hữu cơ ( $\mathrm{N}$ hữu cơ) là đạm số $(\mathrm{Nts})$ trừ đi đạm ammonium $\left(\mathrm{NH}_{4}-\mathrm{N}\right)$. Hàm lượng đạm hữu cơ dễ phân hủy ( $\mathrm{N}$ labile) được phân tích theo phương pháp Gianello and Bremner (1986). Dung trọng đất được xác định bằng ống trụ kim loại (Ring) ngoài đồng ở trạng thái tự nhiên sau đó sấy khô kiệt để tính trọng lượng. Thành phần cơ giới của đất xác định theo phương pháp Robinson.

\subsubsection{Phuoong pháp đánh giá các chỉ tiêu nông hoc và năng suất}

Chiều cao cây $(\mathrm{cm})$ : dữ liệu liên quan đến chiều cao cây được ghi nhận bằng thước cây ở bốn giai đoạn sinh của cây, bằng cách đo từ bề mặt đất đến đỉnh sinh trưởng thân chính của cây đậu bắp. Đường kính thân $(\mathrm{cm})$ được đo tại vị trí lá đầu tiên tính tù̀ mặt đất, đo bằng thước kẹp chia vạch. Chỉ số diệp lục tố (chlorophyll content index) được đo bằng máy SPAD, đo lá thứ 3 tính từ trên xuống. Độ Brix (\%): ghi nhận từ mỗi đợt thu mẫu bằng máy đo khúc xạ kế (Hand Refractometer). Dịch trích của trái đậu bắp được trộn kỹ và giọt nước ép lấy từ dịch trích được đặt trên phiến Refractometer. Brix được quan sát thông qua kết quả hiển thị trên khúc xạ kế. Hàm lượng nitrate trong trái đậu bắp tươi được phân tích theo phương pháp so màu ở bước sóng $410 \mathrm{~nm}$ với thuốc thử axit phenoldisulfonic trong môi trường kiềm theo TCVN 8742:2011. Chiều dài trái và chiều rộng trái được xác định tại thời điểm thu hoạch. Trọng lượng trái $(\mathrm{g})$ : cân từng trái riêng lẻ của mỗi lặp lại sau mỗi lần thu mẫu. Năng suất trái (g/chậu), số trái/cây: tổng trọng lượng các trái được cân trong các đợt thu mẫu. Trái được thu mỗi ngày 1 lần. Các trái được thu là trái đủ non phù hợp cho việc tiêu thụ.

\subsection{Phân tích thống kê}

Các số liệu được tổng hợp, tính toán bằng phần mềm Excel 2013 và được kiểm định ANOVA bằng phần mềm thống kê Minitab 16.0 và sử dụng phép thử Duncan mức ý nghĩa $1 \%$ và $5 \%$ để đánh giá mức độ khác biệt ý nghĩa.

\section{KẾT QUẢ VÀ THẢO LUẬN}

\section{1. Ảnh hưởng của lượng và loại phân bón đến sinh trưởng của đậu bắp đỏ}

Chiều cao cây: Kết quả từ thí nghiệm cho thấy chiều cao cây đậu bắp không bị ảnh hưởng bởi liều lượng phân bón khác nhau trong giai đoạn $7-80$ NSKT nhưng bị ảnh hưởng bởi loại phân lúc 80 NSKT (Bảng 3). Chiều cao cây có bón phân trùn quế khác biệt không ý nghĩa qua phân tích thống kê so với bón phân hóa học và phân gà qua các thời điểm khảo sát. Liều lượng NPK không làm tăng chiều cao cây. Loại phân bón có ảnh hưởng đến chiều cao cây tại thời điểm 80 NSKT. Kết quả phân tích tương tác cho thấy có mối tương tác giữa liều lượng phân bón và loại phân bón ở tất cả các thời điểm quan sát. Ngoại trừ giai đoạn 7 NSKT. Theo IAR (1985) chiều cao cây đậu bắp do yếu tố di truyền quyết định. Theo Ajari et al. (2003) và Aniefiok (2013), trong canh tác đậu bắp, phân hữu cơ đặc biệt là phân gia cầm (gà, vịt) giúp gia tăng chiều cao cây trồng khi so sánh với các nguồn phân khác.

Bảng 3. Ảnh hưởng của loại phân bón và liều lượng phân $\mathrm{N}-\mathrm{P}_{2} \mathrm{O}_{5}-\mathrm{K}_{2} \mathrm{O}$ đến chiều cao cây đậu bắp đỏ theo thời gian sinh trưởng

\begin{tabular}{|c|c|c|c|c|c|c|}
\hline \multirow{2}{*}{ Nhân tố } & & \multicolumn{5}{|c|}{ Ngày sau khi trồng } \\
\hline & & 7 & 15 & 30 & 55 & 80 \\
\hline \multirow{3}{*}{ (A) Lượng phân } & $\mathrm{N}_{120} \mathrm{P}_{60} \mathrm{~K}_{60}$ & 8,94 & 18,2 & 53,0 & 98,6 & 135,8 \\
\hline & $\mathrm{N}_{60} \mathrm{P}_{30} \mathrm{~K}_{30}$ & 10,2 & 20,3 & 56,3 & 106,6 & 127,4 \\
\hline & $\mathrm{N}_{30} \mathrm{P}_{30} \mathrm{~K}_{30}$ & 8,83 & 18,1 & 51,2 & 95,6 & 124,3 \\
\hline \multirow{7}{*}{ (B) Loại phân } & Phân hóa học & 9,35 & 20,0 & 51,2 & 100,1 & $132,3^{\mathrm{ab}}$ \\
\hline & Phân trùn quế & 9,81 & 19,5 & 57,2 & 100,2 & $114,8^{\mathrm{b}}$ \\
\hline & Phân gà & 8,88 & 17,1 & 52,7 & 100,5 & $138,4^{\mathrm{a}}$ \\
\hline & $\mathrm{F}(\mathrm{A})$ & $\mathrm{ns}$ & $\mathrm{ns}$ & $\mathrm{ns}$ & $\mathrm{ns}$ & $\mathrm{ns}$ \\
\hline & $\mathrm{F}(\mathrm{B})$ & ns & $\mathrm{ns}$ & $\mathrm{ns}$ & ns & * \\
\hline & $F(A \times B)$ & ns & $*$ & * & $*$ & * \\
\hline & $\mathrm{CV}(\%)$ & 16,4 & 15,3 & 14,3 & 16,2 & 13,9 \\
\hline
\end{tabular}

Ghi chú: trong cùng một cột tuoong úng với mỗi nhân tố (A hoặc B), giá trị trung bình theo sau có chũ cái theo sau giống nhau thì không khác biệt ý nghĩa thống kê, các chĩ theo sau có chĩ cái khác nhau $(a, b, c)$ thì khác biệt ở múc ý nghĩa $5 \%$ (*) với kiểm định Duncan, ns: khác biệt không ý nghĩa thống kê. 
Đương kính thân: Kết quả thu thập, đánh giá đường kính thân cây đậu bắp (Bảng 4) cho liều lượng phân bón chỉ ảnh hưởng đến đường kính gốc thân cây đậu bắp ở giai đoạn đầu (15 NSKT). Đường kính gốc lớn nhất $(0,88 \mathrm{~cm})$ ở liều bón $\mathrm{N}_{120} \mathrm{P}_{60} \mathrm{~K}_{60}$, kế đến bón $\mathrm{N}_{60} \mathrm{P}_{30} \mathrm{~K}_{30}(0,75 \mathrm{~cm})$ và thấp nhất $(0,66$ $\mathrm{cm}$ ) ở liều bón $\mathrm{N}_{30} \mathrm{P}_{30} \mathrm{~K}_{30}$. Loại phân bón không ảnh hưởng đến đường kính gốc thân cây đậu bắp ở thời điểm 15 NSKT, giai đoạn từ 30 - 80 NSKT loại phân bón có ảnh hưởng rõ rệt đến đường kính gốc thân. Bón phân gà hữu cơ giúp đường kính cây đạt giá trị lớn $(1,21 \mathrm{~cm}-1,87 \mathrm{~cm})$ khác biệt ý nghĩa thống kê (p <0,05) so với bón phân hóa học $(1,26 \mathrm{~cm}$ $1,57 \mathrm{~cm})$ và phân trùn quế $(1,01 \mathrm{~cm}-1,18 \mathrm{~cm})$. Kết quả phân tích tương tác (liều lượng phân x loại phân) cho thấy đường kính cây đậu bắp có ảnh hưởng tác tác với liều lượng phân và loại phân ở mức ý nghĩa $5 \%$.

Bảng 4. Ảnh hưởng của loại phân bón và liều lượng phân $\mathrm{N}-\mathrm{P}_{2} \mathrm{O}_{5}-\mathrm{K}_{2} \mathrm{O}$ đến đường kính gốc thân cây đậu bắp theo thời gian sinh trưởng (ngày sau khi trồng)

\begin{tabular}{|c|c|c|c|c|c|}
\hline \multirow{2}{*}{ Nhân tố } & & \multicolumn{4}{|c|}{ Ngày sau khi trồng } \\
\hline & & 15 & 30 & 55 & 80 \\
\hline \multirow{3}{*}{$\begin{array}{l}\text { (A) Liều lượng } \\
\text { phân }\end{array}$} & $\mathrm{N}_{120} \mathrm{P}_{60} \mathrm{~K}_{60}$ & $0,88^{\mathrm{a}}$ & 1,26 & 1,51 & 1,55 \\
\hline & $\mathrm{N}_{60} \mathrm{P}_{30} \mathrm{~K}_{30}$ & $0,75^{\mathrm{b}}$ & 1,19 & 1,48 & 1,49 \\
\hline & $\mathrm{N}_{30} \mathrm{P}_{30} \mathrm{~K}_{30}$ & $0,66^{\mathrm{c}}$ & 1,05 & 1,47 & 1,49 \\
\hline \multirow{7}{*}{$\begin{array}{l}\text { (B) Loại phân } \\
\text { bón }\end{array}$} & Phân hóa học & 0,76 & $1,26^{\mathrm{a}}$ & $1,56^{\mathrm{b}}$ & $1,57^{\mathrm{b}}$ \\
\hline & Phân trùn quế & 0,77 & $1,01^{\mathrm{b}}$ & $1,18^{\mathrm{c}}$ & $1,18^{\mathrm{c}}$ \\
\hline & Phân gà & 0,69 & $1,21^{\mathrm{ab}}$ & $1,84^{\mathrm{a}}$ & $1,87^{\mathrm{a}}$ \\
\hline & $\mathrm{F}(\mathrm{A})$ & $*$ & $\mathrm{~ns}$ & ns & $\mathrm{ns}$ \\
\hline & $\mathrm{F}(\mathrm{B})$ & ns & $*$ & * & $*$ \\
\hline & $F(A \times B)$ & * & * & * & * \\
\hline & $\mathrm{CV}(\%)$ & 19,3 & 21,3 & 19,5 & 20,8 \\
\hline
\end{tabular}

Ghi chú: trong cùng một cột tuơng úng với mối nhân tố (A hoặc B), giá trị trung bình theo sau có chũ cái theo sau giống nhau thì không khác biệt ý nghĩa thống kê, các chũ theo sau có chũ cái khác nhau $(a, b, c)$ thì khác biệt ở múc ý nghĩa 5\% (*) với kiểm định Duncan, ns: khác biệt không ý nghĩa thống kê.

Chi số diệp lục tố (SPAD): Chỉ số diệp lục tố là một hằng số biểu thị cho tình trạng dinh dưỡng đạm của lá và hàm lượng chlorophyll trong lá quyết định rất lớn đến cường độ quang hợp của lá. Kết quả trình bày tại Bảng 5 cho thấy chỉ số diệp lục tố (SPAD) trong lá đậu bắp đỏ không bị ảnh hưởng bởi liều lượng phân bón tại tất cả các thời điểm theo dõi. Ngược lại, nguồn cung cấp dinh dưỡng có ảnh hưởng rõ rệt đến chỉ số SPAD. Tại các thời điểm theo dõi là 15 NSKT, 30 NSKT, 55 NSKT. Chỉ số diệp lục tố đạt cao nhất ở nghiệm thức bón phân gà, thấp nhất ở nghiệm thức bón phân trùn quế. Giữa bón phân gà và phân hóa học không có sự khác biệt về chỉ số SPAD. Kết quả thí nghiệm đã cho thấy phân hữu cơ gà đã cung cấp nguồn dinh dưỡng cần cho cây trồng lâu hơn và bền hơn phân hóa và phân trùn quế thể hiện quả kết quả theo dõi chỉ số SPAD tại thời điểm 80 NSKT chỉ số SPAD cao nhất khi bón phân gà $(\mathrm{SPAD}=26,4)$, kế đến phân bón hóa học $(\mathrm{SPAD}=20,7)$ và phân bón trùn quế có chỉ số diệp lục thấp nhất (SPAD =14,6), khác biệt có ý nghĩa thống kê. Không tìm thấy mối tương tác giữa liều lượng phân và loại phân bón đến sự thay đổi chỉ số SPAD.

Thông qua kết quả nghiên cứu, phân bón phân hóa học và phân gà giúp cây tăng trưởng tốt hơn phân trùn quế. Trong canh tác đậu bắp có thể sử dụng phân gà thay thế phân hóa học. Bón phân gà hay phân hóa học giúp chiều cao cây, đường kính gốc thân và chỉ số SPAD tốt hơn so với bón phân trùn quế. Điều này có thể do hàm lượng hữu dụng có trong phân gà và hóa học cao hơn phân trùn quế. Giữa phân gà hữu cơ và phân trùn quế, phân gà có $\mathrm{N}$ hữu cơ dễ phân hủy cao, tỷ số $\mathrm{C} / \mathrm{N}$ thấp $(\mathrm{C} / \mathrm{N}=$ 11,93 ) phù hợp cho sự khoáng hóa $\mathrm{N}$ (Bảng 1 ). Theo Groot and Houba (1995) có thể dựa vào thành phần $\mathrm{N}$ hữu cơ dễ phân hủy để dự đoán khả năng cung cấp $\mathrm{N}$ của đất do $\mathrm{N}$ hữu cơ dễ phân hủy có tương quan chặt với sự khoáng hóa $\mathrm{N}$ trong đất.

Kết quả nghiên cứu của Makindae and Ayoola (2012) cũng có ghi nhận tương tự. Phân gà có tác dụng giống như phân bón chậm tan cung cấp dinh dưỡng từ từ đáp ứng đủ nguồn dinh dưỡng cây trồng trong suốt quá trình sinh trưởng phát triển. Ngoài $\mathrm{N}$, trong phân gà còn chứa các chất dinh dưỡng thiết yếu cần cho cây như $\mathrm{Mg}$, Ca giúp cây quang hợp tốt (chỉ số SPAD cao) là tiền đề giúp gia tăng năng suất, gia tăng độ ngọt sản phẩmTheo Shin et al. (1998), hoạt động quang hợp tăng ngoài việc giúp năng suất gia tăng còn giúp hàm lượng đường trong trái cây tăng. Sanwal et al. (2007) kết luận chất diệp lục tố là một phân tử sinh học cực kỳ quan trọng, rất quan 
trọng trong quá trình quang hợp, cho phép cây trồng hấp thụ năng lượng từ ánh sáng. Việc tăng cường bón phân hữu cơ có chứa lượng magie $(\mathrm{Mg})$ cao có thể giúp tổng hợp chất diệp lục, do đó làm tăng tốc độ quang hợp. Theo Shrestha et al. (2012), chỉ số diệp lục tố có tương quan thuận với độ xanh của lá và hàm lượng $\mathrm{N}$ trong lá. Kết quả phân tích tương tác cho thấy liều lượng phân bón và nguồn cung cấp dinh dưỡng khác nhau không có ảnh hưởng tương tác đến chỉ số diệp lục tố của lá.

Bảng 5. Ảnh hưởng của loại phân bón và liều lượng phân $\mathrm{N}_{-} \mathrm{P}_{2} \mathrm{O}_{5}-\mathrm{K}_{2} \mathrm{O}$ đến sự thay đổi chỉ số diệp lục tố (SPAD) trong lá theo thời gian sinh trưởng của cây đậu bắp đỏ

\begin{tabular}{|c|c|c|c|c|c|}
\hline \multirow{2}{*}{ Nhân tố } & & \multicolumn{3}{|c|}{ Ngày sau khi trồng } & \multirow[b]{2}{*}{80} \\
\hline & & 15 & 30 & 55 & \\
\hline \multirow{3}{*}{$\begin{array}{l}\text { (A) Liều lượng } \\
\text { phân }\end{array}$} & $\mathrm{N}_{120} \mathrm{P}_{60} \mathrm{~K}_{60}$ & 15,1 & 22,7 & 22,2 & 21,7 \\
\hline & $\mathrm{N}_{60} \mathrm{P}_{30} \mathrm{~K}_{30}$ & 14,4 & 21,2 & 20,1 & 21,4 \\
\hline & $\mathrm{N}_{30} \mathrm{P}_{30} \mathrm{~K}_{30}$ & 14,0 & 19,1 & 19,5 & 19,3 \\
\hline \multirow{7}{*}{$\begin{array}{l}\text { (B) Loại phân } \\
\text { bón }\end{array}$} & Phân hóa học & $14,1^{\mathrm{ab}}$ & $20,1^{a}$ & $21,5^{\mathrm{a}}$ & $20,7^{\mathrm{b}}$ \\
\hline & Phân trùn quế & $13,4^{\mathrm{b}}$ & $14,1^{\mathrm{b}}$ & $15,1^{\mathrm{b}}$ & $14,6^{\mathrm{c}}$ \\
\hline & Phân gà & $16,1^{\mathrm{a}}$ & $28,2^{\mathrm{a}}$ & $24,5^{\mathrm{a}}$ & $26,4^{\mathrm{a}}$ \\
\hline & $\mathrm{F}(\mathrm{A})$ & $\mathrm{ns}$ & $\mathrm{ns}$ & $\mathrm{ns}$ & $\mathrm{ns}$ \\
\hline & $\mathrm{F}(\mathrm{B})$ & * & * & * & * \\
\hline & $F(A \times B)$ & ns & $\mathrm{ns}$ & ns & ns \\
\hline & CV (\%) & 15,8 & 31,7 & 26,2 & 26,4 \\
\hline
\end{tabular}

Ghi chú: trong cùng một cột tương úng với mỗi nhân tố (A hoặc B), giá trị trung bình theo sau có chũ cái theo sau giống nhau thì không khác biệt ý nghĩa thống kêe, các chũ theo sau có chũ cái khác nhau $(a, b, c)$ thì khác biệt ở mức ý nghĩa $5 \%$ (*) với kiểm định Duncan, ns: khác biệt không ý nghĩa thống kê.

\section{2. Ảnh hưởng của lượng và loại phân bón đến chiều dài trái, đường kính trái và năng suất trái đậu bắp đỏ}

Kết quả trình bày Bảng 6 cho thấy lượng phân bón không ảnh hưởng đến chiều dài trái và đường kính trái. Tuy nhiên, lượng phân bón có ảnh hưởng rõ rệt đến số trái/cây và năng suất trái. Tăng lượng phân bón $(\mathrm{N}, \mathrm{P}, \mathrm{K})$ giúp gia tăng số trái/cây và năng suất trái. Lượng bón $\mathrm{N}_{120} \mathrm{P}_{60} \mathrm{~K}_{60}$ cho số trái/cây và năng suất trái cao nhất $\mathrm{N}_{60} \mathrm{P}_{30} \mathrm{~K}_{30}$. Số trái/cây và năng suất trái thấp nhất ở lượng bón $\mathrm{N}_{30} \mathrm{P}_{30} \mathrm{~K}_{30}$. Bảng 6 cho thấy loại phân bón có đáng kể đến đường kính trái, trọng lượng trái và năng suất trái. Bón phân hóa học và phân gà làm gia tăng đường kính trái, số trái/cây, năng suất trái. Phân trùn quế cho đường kính trái, số trái/cây, năng suất trái thấp nhất.

Điều này có nghĩa, tăng lượng phân bón giúp tăng năng suất. Phân trùn quế có đường kính trái số trái/cây và năng suất trái thấp nhất. Một trong những nguyên nhân dẫn đến phân trùn quế kém hiệu quả hơn phân gà là do phân trùn quế có tỷ số $\mathrm{C} / \mathrm{N}$ cao $(\mathrm{C} / \mathrm{N}=16,05), \mathrm{N}$ - hữu cơ dễ phân hủy trong phân thấp dẫn đến khả năng cung cấp dinh dưỡng cho cây kém (Bảng 1). Thực tế, đã có nhiều nghiên cứu ghi nhận khi một loại phân hữu cơ có tỷ số $\mathrm{C} / \mathrm{N}$ cao được thêm vào đất, quần thể vi sinh vật sẽ cạnh tranh với cây trồng để lấy $\mathrm{N}$ trong đất, lúc này xảy ra hiện tượng cố định N/ bất động N (Amlinger et al., 2003), cây không hấp thu được đủ $\mathrm{N}$ để phát triển. Ngược lại, tỷ số $\mathrm{C} / \mathrm{N}$ của phân gà thấp, khả năng phóng thích dinh dưỡng cao, đáp ứng được nhu cầu phát triển của cây, giúp cây quang hợp tốt, thúc đầy sự phát triển của bộ rễ, dẫn đến gia tăng đường kính trái.

Kết quả thí nghiệm cho thấy cây đậu bắp phản ứng như nhau với việc bón phân gà hữu cơ hay phân hóa học bởi vì thành phần năng suất (số trái/cây) và năng suất trái $(\mathrm{g} / \mathrm{chậu})$ như nhau về mặt thống kê. Bón phân trùn quế cho thành phần năng suất (số trái/cây) và năng suất trái (g/chậu) thấp nhất, khác biệt ý nghĩa thống kê so với bón phân hóa học hay phân gà hữu cơ. Có thể sử dụng phân gà làm nguồn dinh dưỡng cho cây đậu bắp thay thế phân bón hóa học. Kết quả phân tích tương tác cho thấy lượng phân và loại phân có ảnh hưởng rõ rệt đến thành phần năng suất (số trái/cây) và năng suất ở mức ý nghĩa $1 \%$. Việc bón đúng liều lượng phân và loại phân sẽ giúp gia tăng đáng kể số trái/cây và năng suất đậu bắp. 
Bảng 6. Ảnh hưởng của loại phân bón và liều lượng phân $\mathrm{N}-\mathrm{P}_{2} \mathrm{O}_{5}-\mathrm{K}_{2} \mathrm{O}$ đến chiều dài trái, đường kính trái và năng suất trái đậu bắp đỏ

\begin{tabular}{|c|c|c|c|c|c|}
\hline \multicolumn{2}{|l|}{ Nhân tố } & \multicolumn{2}{|c|}{$\begin{array}{l}\text { Dài trái Đường kính trái } \\
(\mathbf{c m})\end{array}$} & \multirow{2}{*}{$\begin{array}{r}\text { Số trái/cây } \\
\text { (trái) }\end{array}$} & \multirow{2}{*}{$\begin{array}{r}\begin{array}{r}\text { Năng suất } \\
\text { (g/châau) }\end{array} \\
217^{\mathrm{a}}\end{array}$} \\
\hline \multirow{3}{*}{$\begin{array}{l}\text { (A) Liều lượng } \\
\text { phân }\end{array}$} & $\mathrm{N}_{120} \mathrm{P}_{60} \mathrm{~K}_{60}$ & 10,0 & 1,65 & & \\
\hline & $\mathrm{N}_{60} \mathrm{P}_{30} \mathrm{~K}_{30}$ & 11,3 & 1,63 & $13,0^{\mathrm{ab}}$ & $175^{\mathrm{ab}}$ \\
\hline & $\mathrm{N}_{30} \mathrm{P}_{30} \mathrm{~K}_{30}$ & 11,7 & 1,58 & $8,22^{\mathrm{b}}$ & $113^{\mathrm{b}}$ \\
\hline \multirow{7}{*}{$\begin{array}{l}\text { (B) Loại phân } \\
\text { bón }\end{array}$} & Phân hóa học & 11,7 & $1,67^{\mathrm{a}}$ & $13,2^{\mathrm{a}}$ & $182^{\mathrm{a}}$ \\
\hline & Phân trùn quế & 10,1 & $1,55^{\mathrm{b}}$ & $6,62^{\mathrm{b}}$ & $97^{\mathrm{b}}$ \\
\hline & Phân gà & 11,1 & $1,64^{\mathrm{a}}$ & $16,8^{\mathrm{a}}$ & $225^{\mathrm{a}}$ \\
\hline & $\mathrm{F}(\mathrm{A})$ & ns & ns & $*$ & $*$ \\
\hline & $\mathrm{F}(\mathrm{B})$ & ns & $*$ & $*$ & $*$ \\
\hline & $F(A \times B)$ & ns & ns & * & * \\
\hline & CV $(\%)$ & 15,5 & 5,55 & 25,3 & 23,2 \\
\hline
\end{tabular}

Ghi chú: trong cùng một cột tương ứng với mỗi nhân tố (A hoặc B), giá trị trung bình theo sau có chũ cái theo sau giống nhau thì không khác biệt ý nghĩa thống kê, các chĩ theo sau có chũ cái khác nhau $(a, b, c)$ thì khác biệt ở mức ý nghĩa $5 \%$ (*) với kiểm định Duncan, ns: khác biệt không ý nghĩa thống kê.

\section{3. Ảnh hưởng của lượng phân và loại phân đến chỉ số độ Brix và hàm lượng nitrate trong trái đậu bắp tươi}

Kết quả đánh giá độ Brix và hàm lượng nitrate trong trái đậu bắp tươi (Hình 1 ) cho thấy lượng phân bón không ảnh hưởng đến độ Brix trái đậu bắp nhưng có ảnh hưởng đến sự tích lũy hàm lượng nitrate trong trái. Hàm lượng nitrate cao nhất ở mức bón $120 \mathrm{~N}(25,6 \mathrm{mg} / \mathrm{kg})$ và thấp nhất ở mức bón $30 \mathrm{~N}$
$(18,4 \mathrm{mg} / \mathrm{kg})$. Nồng độ nitrate $\left(\mathrm{NO}_{3}^{-}\right)$là một trong những đặc tính quan trọng đánh giá chất lượng rau. Theo quy định chung của thế giới, để được gọi là rau sạch, rau tươi phải có lượng nitrate $\left(\mathrm{NO}_{3}^{-}\right)$thấp vừa phải. Kết quả phân tích cho thấy hàm lượng nitrate trong trái đậu bắp tươi dao động trong khoảng 18,4 - 25,6 mg/kg, thấp hơn ngưỡng nitrate tối đa cho phép trong trái đậu bắp tươi theo Tổ chức $\mathrm{Y}$ tế Thế giới (WHO) là $200 \mathrm{mg} / \mathrm{kg}$ trái tươi.

口Brix (\%)

口NO3 mg/kg

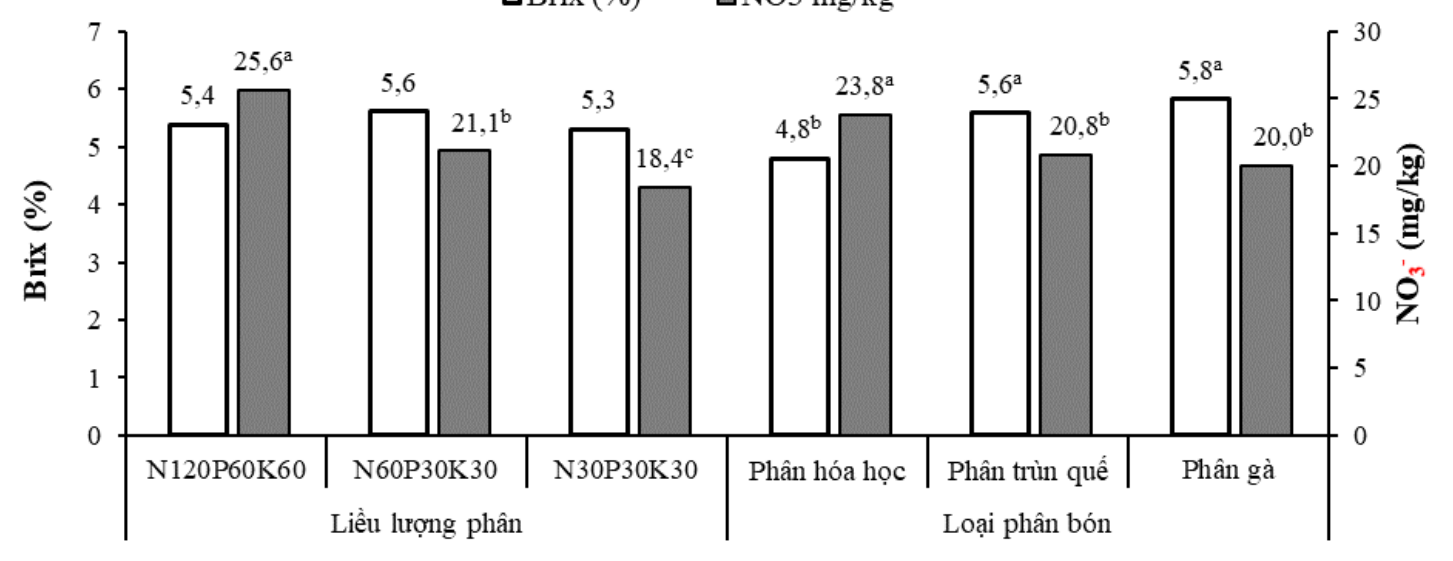

Nghiệm thức

Hình 1. Ảnh hưởng của loại phân và liều lượng phân N-P $\mathrm{P}_{2} \mathrm{O}_{5}-\mathrm{K}_{2} \mathrm{O}$ độ Brix và hàm lượng nitrate trong trái đậu bắp đỏ

Ghi chú: Mỗi nhân tố cột có số theo sau chũ giống nhau thì không khác biệt ý nghĩa thống kê $(P<0,01)$

Kết quả thí nghiệm cũng cho thấy loại phân bón có ảnh đáng kể độ Brix và sự tích lũy nitrate trong trái đậu bắp. Bón phân hóa học có độ Brix thấp nhất và hàm lượng $\mathrm{NO}_{3}{ }^{-}$cao nhất. Ngược lại, bón phân hữu cơ (phân gà và phân trùn quế) cho độ Brix cao và hàm lượng $\mathrm{NO}_{3}{ }^{-}$thấp. Kết quả phân tích tương tác cho thấy lượng phân và loại phân có ảnh hưởng rõ rệt đến chỉ số Brix và hàm lượng nitrate trong trái 
ở mức ý nghĩa 1\%. Theo Ávila-Juárez et al. (2015), độ Brix của trái là một chỉ số về chất lượng bị chi phối bởi các yếu tố như di truyền của giống, loại dinh dưỡng, loại đất và các yếu tố khác $(\mathrm{EC}, \mathrm{pH}$, lượng phân bón kali, stress, v.v.). Sử dụng phân hữu cơ làm tăng đáng kể hàm lượng acid hữu cơ (acid malic acid, quinic acid và citric acid), đường (fructose, glucose và tổng đường) (Shiow \& ShinShan, 2002), chất rắn hòa tan và chất rắn không hòa tan (Gutiérrez-Miceli et al., 2007) dẫn đến gia tăng độ ngọt của trái. Theo Nguyễn Thanh Thịnh và ctv. (2010), độ ngọt của trái sẽ gia tăng khi cây hấp thu đủ kali. Ngược lại, trong canh tác nếu bón nhiều đạm có thể gây ức chế sự hấp thụ đối với kali mà việc thiếu kali sẽ làm cho trái giảm sự tích lũy các carbohydrate hòa tan, gia tăng sự tích lũy các hợp chất đạm hòa tan dẫn đến độ ngọt của trái giảm.

\section{KẾT LUẬN VÀ ĐỀ NGH!}

Liều lượng phân bón có ảnh hưởng đến kể đến sự tăng trưởng, năng suất và chất lượng trái đậu bắp đỏ. Tăng liều lượng NPK giúp tăng chiều cao cây, đường kính gốc thân, chỉ số diệp lục tố (SPAD), đường kính trái, chiều dài trái, độ Brix, số trái/cây, năng suất trái, và hàm lượng nitrate trong trái tươi. Loại phân bón có ảnh hưởng rõ rệt đến chiều cao cây, đường kính gốc thân, chỉ số diệp lục tố, đường kính trái, số trái/cây, năng suất trái tươi, độ Brix và hàm lượng nitrate trong trái tươi. Bón phân hóa học hay phân gà cho số trái/cây và năng suất trái cao hơn bón phân trùn quế. Bón phân hữu cơ (phân gà, phân trùn quế) có độ Brix cao hơn và hàm lượng lượng $\mathrm{NO}_{3}$ thấp hơn bón phân hóa học.

Cần thí nghiệm trên đồng ruộng để đánh giá hiệu quả kinh tế và ảnh hưởng tích lũy sau nhiều vụ của phân trùn quế.

\section{TÀI LIỆU THAM KHẢO}

Ajari, O., Tsado, L. E. K., Oladiran, J. A. and Salako, E. A. (2003). Plant height and fruit yield of okra as affected by field application of fertilizer and organic matter in Bida, Nigeria. The Nigerian Agricultural Journal, 34, 74 - 80.

Ali Mohammadi, A. and Moghadasi, M.S. (2015). The interaction effect of nitrogen and vermicompost on chickpea yield and yield components in Hamedan region. Biological Forum - An International Journal, 7(2), 812-816.

Amlinger, F., Götz, B., Dreher, P., Geszti, J., \& Weissteiner, C. (2003). Nitrogen in biowaste and yard waste compost: dynamics of mobilisation and availability - A review. European Journal of Soil Biology, 39(3), 107-116.
András, C. D., Simándi, B., Örsi, F., Lambrou, C., Missopolinou-Tatala, D., Panayiotou, C., ... \& Doleschall, F. (2005). Supercritical carbon dioxide extraction of okra (Hibiscus esculentus L) seeds. Journal of the Science of Food and Agriculture, 85(8), 1415-1419.

Aniefiok, I. A. (2013). Effects of Poultry Manure and Plant Spacing on the Growth and Yield of Waterleaf (Talinum fructicosum L. Juss). Journal of Agronomy, 12(3): 146-152.

Arancon, N. Q., Edwards, C. A., Bierman, P., Metzger, J. D., Lee, S., \& Welch, C. (2003). Effects of vermicomposts on growth and marketable fruits of field-grown tomatoes, peppers and strawberries: the 7 th international symposium on earthworm ecology. Cardiff. Wales· 2002. Pedobiologia, 47(5-6), 731-735.

Ávila-Juárez, L., Rodríguez González, A., Rodríguez Piña, N., Guevara González, R. G., Torres Pacheco, I., Ocampo Velázquez, R. V., \& Moustapha, B. (2015). Vermicompost leachate as a supplement to increase tomato fruit quality. Journal of soil science and plant nutrition, 15(1), 46-59.

Gutiérrez-Miceli, F. A., Santiago-Borraz, J., Molina, J. A. M., Nafate, C. C., Abud-Archila, M., Llaven, M. A. O., ... \& Dendooven, L. (2007). Vermicompost as a soil supplement to improve growth, yield and fruit quality of tomato (Lycopersicum esculentum). Bioresource Technology, 98(15), 2781-2786.

Groot, J. J. R., \& Houba, V. J. G. (1995). A comparison of different indices for nitrogen mineralization. Biology and Fertility of Soils, 19(1), 1-9.

Gul, K., Singh, A. K. and Jabeen, R. (2015). Nutraceuticals and Functional Foods: The Foods for Future World, Critical Reviews in Food Science and Nutrition. DOI: 10.1080/10408398.2014.903384

Gunawardhana, M. D. M., De Silva, C. S., and Godawatta, V. N. A. (2011). Impact of temperatureand water stress on growth and yield of selected crops. International Conference on Impact of Climate Change on Agriculture, University of Ruhuna, Mapalana Kamburupitiya. Dec 20th 2011, pp. 150-157.

IAR (1985). Annual Reports. Institute of Agric. Research Samaru, ABU, Zaria.

Irshad, M., Debnath, B., Mitra, S., Arafat, Y., Li, M., Sun, Y. and Qiu, D. (2018). Accumulation of anthocyanin in callus cultures of red pod okra [Abelmoschus esculentus (L) Hongjiao] in response to light and nitrogen. Plant Cell Tiss Organ Cult. 134(1), 29-39.

Khandaker, M.M., Jusoh, N., Ralmi, N.H., and Ismail, S. Z. (2017). The effect of different types of organic 
fertilizers on growth and yield of Abelmoschus esculentus (L.) Moench (okra). Bulgarian Journal of Agriculture Science, 23(1), 119-125.

Li, J., Cooper, J. M., Lin, Z. A., Li, Y., Yang, X., and Zhao, B. (2015). Soil microbial community structure and function are significantly affected by long-term organic and mineral fertilization regimes in the North China Plain. Applied Soil Ecology, 96, 75-87.

Mahajan, A., Bhagat, R.M., and Gupta, R.D. (2008). Integrated Nutrient Management in sustainable Rice-Wheat cropping system for Food security in India. SAARC J. Agri. 6(2), 29-32.

Masciandaro, G., Ceccanti, B., and Gracia C. (1997). Soil agro-ecological management: fertigation and vermicompost treatments. Bioresour Technol., 59,199-206.

Nguyễn Thanh Thịnh, Nguyễn An Đệ và Bùi Xuân Khôi. (2010). Ảnh hưởng mức phân bón N, P, K đến năng suất cây mít Nghệ trên đất xám tại miền Đông Nam Bộ. Kết quả nghiên cứu khoa học công nghệ rau quả 2007-2008. Nxb. Nông Nghiệp, trang 252-262.

Phillip, H., Eric, O., Weerasooriya, A. and Ampim, P. (2019). Economic potential of okra cultivation for limited resource farmers. Pursue: Undergraduate Research Journal, 2(1), Article 2.

Polturak, G., Grossman, N., Vela-Corcia, D., Dong, Y., Nudel, A., Pliner, M., ... \& Aharoni, A. (2017). Engineered gray mold resistance, antioxidant capacity, and pigmentation in betalain-producing crops and ornamentals. Proceedings of the National Academy of Sciences, 114(34), 9062-9067.

Sanwal, S. K., Lakminarayana, K., Yadav, R. K., Rai, N., Yadav, D. S. and Mousumi, B. (2007). Effect of Organic Manures on Soil Fertility, growth, Physiology, Yield and Quality of Turmeric. Indian Journal of Horticulture, 64(4), 444 - 449.

Shin, Y.S., Do, H.W., Bae, S.G., Choi, S.K., and Choi, B.S. (1998). Effect of CO2 enrichment on quality and yield of oriental melon (Cucumis melo L var. makuwa Mak) in greenhouse. RDA J Agro-Environ Sci; 40, 107-110.

Shiow, Y.W. and Shin - Shan L. (2002). Composts as soil supplement enhanced plant growth and fruit quality of strawberry. Journal of Plant Nutrition, 25(10), 2243- 2259.

Shrestha, S., Brueck, H., and Asch, F. (2012). Chlorophyll index, photochemical reflectance index and chlorophyll fluorescence measurements of rice leaves supplied with different N levels, Journal of Photochemistry and Photobiology B: Biology, 113, 7 - 13.

Zaremanesh, H., Nasiri, B., and Amir, A. (2017). The effect of vermicompost biological fertilizer on corn yield. J. Mater. Environ. Sci., 8(1), 154-159.

Zucco, M. A.; Walters, S. A., Chong, S. K., Klubek, B. P. and Masabni, J.G. (2015). Effect of soil type and vermicompost applications on tomato growth. International Journal of Recycling of Organic Waste in Agriculture, 4, 135-141. 